\title{
Training in the year of the eye: the impact of the COVID-19 pandemic on ophthalmic education
}

\author{
Shaunak K Bakshi (10), ${ }^{1}$ Allen C Ho, ${ }^{2}$ James Chodosh (D), ${ }^{3}$ \\ Adrian T Fung, ${ }^{4,5}$ R V Paul Chan, ${ }^{6}$ Daniel Shu Wei Ting (1) ${ }^{7}$
}

\section{INTRODUCTION}

At the dawn of the new decade, the year 2020 heralded an auspicious occasion for ophthalmologists worldwide. Thus far, however, it has been marked by great challenges and stress, with the global outbreak of the SARS-CoV-2 virus. The resulting COVID19 pandemic, with over 8 million estimated confirmed cases as of June $17,{ }^{1}$ has placed an overwhelming burden on healthcare systems throughout the world, from Wuhan (China) to Bergamo (Italy) and New York City (USA). Physical distancing measures have been implemented widely to stem transmission, with large-scale lockdowns in place currently in numerous countries. With the allocation of resources towards COVID-19 management, and escalation of attempts to reduce spread, clinic visits and elective surgeries have been minimised or cancelled altogether. In ophthalmology, for clinical encounters that are still occurring, a variety of practices have been adopted to protect asymptomatic patients and providers. ${ }^{2} 3$ Overall, however, in the midst of this global crisis, clinical activity within eye care has significantly diminished. Given this, how are our ophthalmologists-in-training continuing to learn? The downstream effects of COVID-19 have influenced the educational experience of both trainees and practicing clinicians around the world.

\footnotetext{
${ }^{1}$ Harvard Medical School, Boston, Massachusetts, USA ${ }^{2}$ The Retina Service of Wills Eye Hospital, Mid Atlantic Retina, Philadelphia, Pennsylvania, USA

${ }^{3}$ Ophthalmology, Massachusetts Eye and Ear, Howe Laboratory, Harvard Medical School, Boston,

Massachusetts, USA

${ }^{4}$ Discipline of Clinical Ophthalmology and Eye Health, Faculty of Medicine and Health, The University of Sydney, Sydney, Australia

${ }^{5}$ Department of Ophthalmology, Faculty of Medicine, Health and Human Sciences, Macquarie University, Sydney, Australia

${ }^{6}$ Retina, Illinois Eye and Ear Infirmary, Chicago, Illinois, USA

${ }^{7}$ Vitreo-Retinal Department, Singapore National Eye Center, Singapore, Singapore
}

Correspondence to Dr Daniel Shu Wei Ting, Singapore National Eye Centre, Duke-NUS Medical School, Singapore 168751, Singapore;

Daniel.ting.s.w@singhealth.com.sg

\section{CHANGES IN RESIDENCY AND FELLOWSHIP TRAINING \\ Clinical experience}

In some locales with a heavy COVID-19 burden, trainees have been redeployed to emergency departments or intensive care units, temporarily halting their ophthalmic training. For those who have not, providers are frequently organising into separate team units to care for patients, thereby reducing cross-exposure risk. The pandemic has necessitated triage to prioritise urgent cases requiring an examination and possible intervention. Though waiting rooms are not crowded and in-person chronic disease management is less regular, this assessment process may provide a unique learning experience for involved trainees. Further, in some cases, teleophthalmology has been employed for screening and basic visits. While learning may be impacted by the currently limited nature of the virtual ocular examination and the level of patient facility with digital platforms, this is a chance for trainees to gain experience with telemedicine, which will undoubtedly play an increasingly relevant role in all of our careers. This also represents an opportunity to evaluate our current systems and pinpoint where inefficiencies in workflow and disparities in care delivery may exist.

Nevertheless, the substantial reductions in volume present challenges for learners. While many may have gained confidence in their clinical abilities by this time of year, some may not have attained needed surgical numbers. Others may identify desired areas for growth and might choose to pursue observerships or other formally organised experiences in these domains. In the setting of reduced volume as well as disruptions with visa-related and travel complications, the relative utility of fellowships in honing clinical acumen in the coming year will be a topic of continued discussion.

\section{Virtual conferencing and education}

With the advent of physical distancing norms, face-to-face interactions in large numbers are no longer feasible. As such, departmental Grand Rounds, seminars and other didactic sessions have been cancelled or are now held virtually through media such as Zoom. Professional conferences, which allow trainees to present scholarly work, network with others in the community and learn about the latest in ophthalmic innovation, have similarly been cancelled/rescheduled or replaced with virtual counterparts. ${ }^{4}$ However, the growth of webinars, podcasts, and online symposia $^{5-7}$ is allowing interaction, exchange of ideas and continuation of our education remotely. Expansion in the usage of social networks such as Twitter by both trainees and attending clinicians for professional connection and communication has further facilitated information flow and community building. While not completely replacing the experience of inperson interactions with others, these mediums offer considerable utility in teaching and learning from home.

The pandemic has also resulted in adjustments to national board examinations, with varied adoption of virtual methods: the American Academy of Ophthalmology, for example, is exploring at-home testing with its Ophthalmic Knowledge Assessment Program, and the American Board of Ophthalmology is transitioning to a virtual format for its oral examination, ${ }^{8} \quad 9$ while the Royal Australian and New Zealand College of Ophthalmologists has tentatively opted to hold its Advanced Clinical Examinationoriginally scheduled for March-in late October, ${ }^{10}$ deeming a virtual assessment an unsuitable substitute for this hands-on clinical evaluation. Alongside preparation for such examinations, in the absence of direct patient-based learning, residents may benefit from numerous online resources, from simulation exercises ${ }^{11}$ to annotated and/or narrated video libraries such as those hosted by Eyetube and Cataract Coach, which have been growing in development and consumption. As for surgical skill refinement, aside from suturing, knot-tying practice and wetlaboratory training, simulators such as Eyesi may be used to recreate the surgical experience.

Current conditions have forced many to discover and employ already existing systems of communication and information sharing. As a popular example, the adoption of the aforementioned Zoom platform for video conferencing, though marred by privacy concerns, has been nothing short of extraordinary, with over 200 million daily users in March 2020, up from at most 10 million previously. ${ }^{12}$ Within healthcare, many fields have seen 
a significant expansion in telemedicine practices with relaxation in payment restrictions by the Centers for Medicare $\&$ Medicaid Services in the USA. ${ }^{13}$ In ophthalmic education, ongoing needs may serve as a call to action to accelerate the application pipeline of versatile and cost-effective technologies.

\section{Prospective residents: impact on undergraduate medical education}

Beyond the training of residents and fellows, the COVID-19 outbreak has disrupted the educational experience of medical students worldwide. While preclinical curricula have transitioned to virtual instruction, in-person clinical rotations for students have ceased in many areas. In some cases, students in their final year have graduated early to assist with COVID-19 response. At baseline, the time for structured education allotted to ophthalmology during medical school varies significantly, but in general has declined over the years. ${ }^{14}{ }^{15}$ Insufficient exposure, which may result in fewer trainees developing an interest in the field, was cited by students in a study at one US institution ${ }^{16}$ as one of the main reasons for not choosing ophthalmology as their specialty. The cancellation of in-person home and away rotations may further reduce opportunities to obtain experience in ophthalmology, engage with faculty and trainees, conduct research and prepare to apply for residency, though some schools are now offering a virtual ophthalmology elective. Providing an enriching experience that recreates what one may learn peering through a teaching scope in the clinic, or observing a case in the operating room, may require resourceful usage of digital curricula, remote mentoring and introductory simulations. ${ }^{17-19}$ Further, these changes may affect the residency application process itself. $^{20}$ The SF Match service in the USA has adjusted the timeline of the upcoming application cycle, and the Association of American Medical Colleges has encouraged all interviews to be held virtually. ${ }^{21}$

\section{CONTINUING MEDICAL EDUCATION}

Ultimately, ophthalmology is a constantly evolving profession. Our understanding of ocular disease and management continues to advance, and practices considered gold standard today may no longer be relevant in the near future. Indeed, our learning does not end with residency or fellowship. Systems have adapted to the pandemic in various manners, from extension of the 2019 reporting deadline for continuing medical education by the Accreditation Council for Continuing Medical Education in the USA ${ }^{22}$ to a waiver of continuing professional development requirements for 2020 registration renewal by the Medical Board of Australia. ${ }^{23}$ Embracing a growth mindset of persistent self-evaluation, we will continue to develop our models of continuing medical education and expand virtual forums for discussion and sharing of knowledge.

\section{THE NEW NORMAL}

Business as usual in our global society may not resume for the foreseeable future. Within ophthalmology, reductions in clinical volume and cancellation of in-person academic and professional gatherings may endure. However, our systems of medical education will continue, as we cultivate the emerging generation of ophthalmologists and leaders in healthcare. Navigating these challenging times together, both instructors and trainees are continuously adapting to ever-changing conditions. As we identify gaps in training, we will create novel learning methods to fill them and seek opportunities to improve our teaching paradigms. In the process, while in-person, hands-on pedagogy may be ideal for learning, we can use every tool at our disposal creatively, applying modern digital solutions and adopting emerging technologies for virtual instruction, clinical care, and research. ${ }^{24} 25$

Reflecting on our collective vision in 2020 , it is critical for us to stay connected. The climate of the past few months has been characterised by substantial uncertainty and unease. For trainees, the pandemic may bear multiple sources of apprehension, as they consider implications for their education, changes in examination scheduling and milestones, financial and employment concerns, and deferment of personal and professional plans. This may be compounded by fears of exposure for themselves and loved ones, mixed with anxiety around preparation and the challenging experience of caring for affected patients if redeployed. Efforts of ophthalmology training programmes in the New York area serve as an example of the power of collaboration, with implementation of shared lecture programming, telemedicine experiences and emotional support services for residents. ${ }^{26}$ Devoting time to check in with our colleagues, mentors and trainees across the globe may be meaningful in providing mutual support and solidarity. While we may be physically distant, open communication and interaction within our ophthalmic community will foster and maintain resilience and resolve, as we continue to learn and work together to serve our patients in the new normal.

Contributors SKB made substantial contributions to the writing, conceptualisation and editing of the manuscript; DSWT made substantial contributions to the conceptualisation, supervision, critical review and editing of the manuscript; and ACH, JC, ATF, RVPC made substantial contributions to the critical review and editing of the manuscript.

Funding This research received no specific grant from any funding agency in the public, commercial or not-forprofit sectors.

\section{Competing interests None declared.}

Provenance and peer review Not commissioned; internally peer reviewed.

This article is made freely available for use in accordance with BMJ's website terms and conditions for the duration of the COVID-19 pandemic or until otherwise determined by BMJ. You may use, download and print the article for any lawful, non-commercial purpose (including text and data mining) provided that all copyright notices and trade marks are retained.

(C) Author(s) (or their employer(s)) 2020. No commercial re-use. See rights and permissions. Published by BMJ.

\section{A) Check for updates}

To cite Bakshi SK, Ho AC, Chodosh J, et al. Br J Ophthalmol 2020;104:1181-1183.

Received 22 May 2020

Accepted 26 May 2020

Revised 25 May 2020

Br J Ophthalmol 2020;104:1181-1183.

doi:10.1136/bjophthalmol-2020-316991

\section{ORCID iDs}

Shaunak K Bakshi http://orcid.org/0000-0002-91284138

James Chodosh http://orcid.org/0000-0002-7463-1599 Daniel Shu Wei Ting http://orcid.org/0000-0003-22647174

\section{REFERENCES}

1 World Health Organization. Coronavirus disease (COVID-19) pandemic. Available https://www.who.int/ emergencies/diseases/novel-coronavirus-2019 (accessed 18 June 2020).

2 Li JPO, Shantha J, Wong TY, et al. Preparedness among ophthalmologists: during and beyond the COVID-19 pandemic. Ophthalmology 2020;127:569-72.

3 Li J-PO, Lam DSC, Chen Y, et al. Novel coronavirus disease 2019 (COVID-19): the importance of recognizing possible early ocular manifestation and using protective eyewear. $\mathrm{Br} J$ Ophthalmol 2020;104:297-8. 
42020 ASCRS Virtual Annual Meeting. Available https:// ascrs.org/annual-meeting (accessed 16 May 2020).

5 Academy Clinical Webinars. Available https://www. aao.org/clinical-webinars (accessed 29 Apr 2020).

6 Guardians of the Lens Webinar. Available https://www. prismeyeinstitute.com/guardians/ (accessed 29 Apr 2020).

7 BMC virtual spring symposium. Available https://www. bmcvirtual.com/ (accessed 29 Apr 2020).

8 COVID-19 Information Center, American Board of Ophthalmology. Available https://abop.org/covid19\# candidates (accessed 12 May 2020).

9 Bartley GB, COVID-19 and the American Board of Ophthalmology: when the best-laid plans go awry. Ophthalmology 2020; In Press.

102020 RANZCO Examinations Timetable. Available https://ranzco.edu/wp-content/uploads/2020/05/ Revised-2020-RANZCO-Examinations-Timetable -06052020.pdf (accessed 16 May 2020).

11 Cataract Master. Available https://aao-resourcesenformehosting.s3.amazonaws.com/resources/ Cataract_Master/index.html (accessed 29 Apr 2020).

12 Patnaik S. Zoom pulls in more than 200 million daily video users during worldwide lockdowns. Reuters. Available https://www.reuters.com/article/us-healthcoronavirus-zoom/zoom-pulls-in-more-than-200million-daily-video-users-during-worldwide-lockdowns -idUSKBN21K1C7 (accessed Apr 28 2020).
13 Centers for Medicare \& Medicaid Services.

Telemedicine health care provider fact sheet. Available https://www.cms.gov/newsroom/fact-sheets/medicaretelemedicine-health-care-provider-fact-sheet (accessed 29 Apr 2020)

14 Succar T, Grigg J, Beaver HA, et al. A systematic review of best practices in teaching ophthalmology to medical students. Surv Ophthalmol 2016;61:83-94.

15 Moxon NR, Goyal A, Giaconi JA, et al. The state of ophthalmology medical student education in the United States: an update. Ophthalmology 2020; In Press.

16 Linz MO, Jun AS, Clever SL, et al. Evaluation of medical students' perception of an ophthalmology career. Ophthalmology 2018;125:461-2.

17 AAO ophthalmology resources for medical students. Available https://www.aao.org/medical-students (accessed 12 May 2020).

18 Retinoscopy Simulator. Available https://www.aao.org/ interactive-tool/retinoscopy-simulator (accessed 29 Apr 2020).

19 Strabismus Simulator. Available https://www.aao.org/ interactive-tool/strabismus-simulator (accessed 29 Apr 2020)

20 AUPO 2021 ophthalmology match updates. Available https://aamc-orange.global.ssl.fastly.net/ production/media/filer_public/ac/4a/ac4a742e-37d94f9c-9b3b-79944824e8ad/aupo_2021_ophthalmol ogy_match_statement_5820.pdf (accessed 19 May 2020).

21 Conducting interviews during the coronavirus pandemic. Available https://www.aamc.org/whatwe-do/mission-areas/medical-education/conduct ing-interviews-during-coronavirus-pandemic (accessed 19 May 2020)

22 Extended deadline for PARS reporting. Available https://www.accme.org/highlights/extendeddeadline-for-pars-reporting (accessed 16 May 2020).

23 Medical board of Australia responses to COVID-19 pandemic. Available https://www.medicalboard.gov. au/News/2020-03-30-COVID19-Board-response.aspx (accessed 16 May 2020)

24 Ting DSW, Carin L, Dzau V, et al. Digital technology and COVID-19. Nat Med 2020;26:459-61.

25 Ting DSW. Digital transformation in health care during and beyond COVID-19. MIT Technology Review Insights. Available https://insights.techre view.com/digital-transformation-in-health-careduring-and-beyond-covid-19/ (accessed 12 May 2020)

26 Chen RWS, Abazari A, Dhar S, et al. Living with COVID-19: a perspective from New York area ophthalmology residency program directors at the epicenter of the pandemic. Ophthalmology 2020; In Press. 